held seriously, not even by George F. Oster and Edward O. Wilson, to whom it is attributed. This looks to me like fighting a straw man. I would have preferred an up-to-date overview on the state-of-art in this field or a thorough analysis of how Gordon's encounter-rate model compares with temporal polyethism (which is mentioned elsewhere in the book) or the many other models of decentralized control and selforganized division of labour. Even readers less familiar with social insects would not have been overtaxed by a balanced treatment of this subject.

To conclude, Ants at Work offers a lot of information on harvester ants and introduces several new, and some not so new, interpretations of ant behaviour, including the concept of self-organization, to a broader audience. This is probably the author's main aim, and it is well achieved. It is doubtful, however, whether the book will satisfy the much farther-reaching aims listed on the dust-jacket. I enjoyed reading the book, but it did not really revolutionize my understanding of ants.

Jürgen Heinze is at the Zoologisches Institut I, Universität Erlangen-Nürnberg, Staudtstrasse 5, D-91058 Erlangen, Germany.

\section{An exobiologist's life search}

Carl Sagan: A Life in the Cosmos

by William Poundstone

Holt: 1999.560 pp. $\$ 30$

Carl Sagan: A Life

by Keay Davidson

Wiley: 1999.540 pp. $\$ 30$

\section{Christopher Chyba}

The astronomer Carl Sagan died of pneumonia in December 1996, following a twoyear struggle with the bone-marrow disease myelodysplasia.

Sagan had directed the Laboratory for Planetary Studies at Cornell University, where his research group pursued questions related to the organic chemistry of the outer

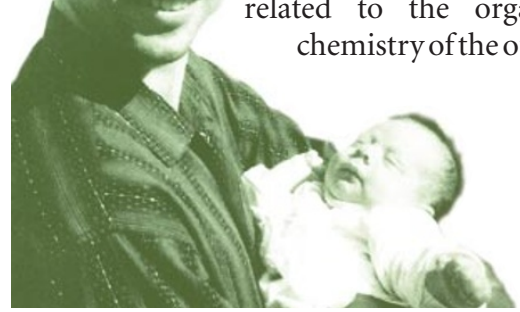

From inner to outer space: Sagan in 1959 holding his and Lynn Margulis' son, Dorion.
Solar System, the origins of life on Earth and the search for life elsewhere.

Always optimistic about the prospects for extraterrestrial life and intelligence, Sagan's early scientific contributions nevertheless considerably diminished hopes for life on Venus and Mars. His subsequent work on the "early faint Sun paradox" set the stage for decades of research trying to reconcile the evolution of the Sun with the early terrestrial greenhouse atmosphere.

Throughout his career, he played a leading role in Solar System exploration, including the Viking and Voyager missions. Sagan's popular book Cosmos (Abacus, 1983), based on his award-winning television series, was the best-selling science book ever published in the English language. At the time of his death, he was undoubtedly the most famous scientist in the United States. He was a vocal enthusiast for the scientific search for extraterrestrial life, a public sceptic about claims for the paranormal and UFO visitations, and had played a prominent public role in the 'nuclear winter' debate, warning of the possible effects that the fires resulting from nuclear war would have on climate. This was a remarkable brew, and guaranteed that his life would prove of unusual interest. His first two biographies have just been published.

Carl Sagan: A Life in the Cosmos is by William Poundstone. His previous book, Prisoner's Dilemma (Doubleday, 1993), was part biography of the mathematician John von Neumann, part popular explanation of game theory and part cold- war history. As a result, Poundstone brings to Sagan's life a feeling for science combined with an intuition for politics and bureaucracy.

Poundstone understands the psychological free-for-all at work when scientists choose which problems to pursue: "These decisions are necessarily intuitive and idiosyncratic, based on incomplete information and personal value judgments. A prime example of this is Sagan and the exobiologists' belief that, of all the possible things we might learn about the universe, the detection of extraterrestrial life would hold unique significance." But he also understands Karl Popper's distinction between this personal realm of hypothesis formation and the intersubjective, though tricky, realm of hypothesis testing. This gives Poundstone's accounts of both exobiology and the nuclear winter controversy some sophistication. About nuclear winter, he writes, "the TTAPS [Richard Turco, O. Brian Toon, Thomas Ackerman, James Pollack and Sagan] group was qualitatively right and quantitatively wrong in their first publication - and then they revised as new data became available. What makes nuclear winter different is that the error-correcting mechanism of science was played out in the political arena."

^ ๑ 1999 Macmillan Magazines Ltd
The second new biography is Carl Sagan: A Life, written by Keay Davidson, a science writer for the San Francisco Examiner newspaper. Both biographies contain a great deal that is unflattering to the young Sagan. Each particularly criticizes Sagan's behaviour in his first marriage to Lynn Alexander (now Lynn Margulis, the biologist). Sagan was 22 and Alexander 19 when they married. Clearly, the union was premature. "The divorce was probably a greater success than the marriage," Poundstone comments dryly.

Neither biographer can be blamed for quoting a divorced spouse, a bitter child of a first marriage or even a long-time friend who chooses to reveal old confidences. Poundstone is interested in Sagan's personal life, but lets those he quotes speak for themselves. Davidson's biography, by contrast, is replete with attributions of motive and unsubstantiated accusations that go well beyond the evidence.

Consider Davidson's description of the teenage Sagan at the University of Chicago (Sagan went to university at 16): "He apparently did not show special favors to women - did not talk down to them, as if they were children - which, one surmises, at least some of them found strange but alluring, like being seduced by someone eager to ravage a previously unravaged part of their bodies: their brains.

"Whether he ravaged anything else is unclear; Sagan left virtually no reminiscences about his college dating habits, and what he did recall was typically self-centered, concerned less with the girl than with how he thought she perceived him."

It is hard to know what to make of this disturbing passage. Quite apart from his strange "surmises" about women, Davidson criticizes Sagan for leaving no reminiscences about his romances with the "girls" he met. No honourable explanation is entertained, such as simple respect for the young women's privacy.

More serious is Davidson's accusation that the young Sagan wilfully and illegally revealed classified information in order to further his chances of winning a Miller Institute graduate fellowship to Berkeley. This is a serious and specific legal allegation which Davidson does not substantiate. Instead, we learn that Sagan was nominated for the Miller fellowship by Nobelist Joshua Lederberg, that the Nobelist H. J. Muller wrote in support that Sagan "stood head and shoulders above" other students of his age and that he had recommendations from the future Nobelist Melvin Calvin and the chair of Berkeley's astronomy department. Yet Davidson claims that these alone were "probably not good enough to ensure his victory" in the fellowship competition. Therefore, he asserts, Sagan revealed the classified information to "make the Miller judges sit up and take notice". 
Davidson writes: "[Sagan] decided to confide to [the fellowship judges] information that he was required by federal law to keep secret. He revealed his research at the Armour Research Foundation on the remote detection of lunar nuclear explosions. He must have known the risk he was taking. The information was classified; he had previously cautioned Muller not to discuss it with others.... Washington did not look kindly on the leaking of nuclear information." The only footnote to this passage reads "Sagan's Miller Fellowship file".

Davidson presents Sagan's request to Muller not to discuss his work as evidence that Sagan knew he should not be revealing it. Davidson faxed me the letter on which he said he based this account: a letter from Sagan to Muller, dated 18 March 1959. The relevant section reads:

"Since [my work on possible primitive lunar organic synthesis] is only a first draft, and since part of it was done on a classified contract - although the enclosed of course is not classified - I would not want extensive distribution of the manuscript at the present time."

Sagan was asking Muller not to distribute an unpublished manuscript, a standard request between scientists. The manuscript was not classified, and had already been sent to five other scientists. The letter, which was Davidson's source, provides no evidence that Sagan was revealing classified information.

What information did Sagan "reveal" in his application? The only relevant part of Sagan's fellowship application (which I examined at the Miller Institute) is the section in which he cites his publications, where he mentions: "Various classified papers on scientific information to be gained from possible lunar nuclear detonations, Physics Research Department, Armour Research Foundation, Chicago."

But classified documents may well have unclassified titles or subsections. To level the grave charge that someone illegally revealed classified nuclear information, a reporter has a responsibility to provide evidence for the allegation. Davidson does not.

In the early 1990s, the National Academy of Sciences denied membership to Sagan.

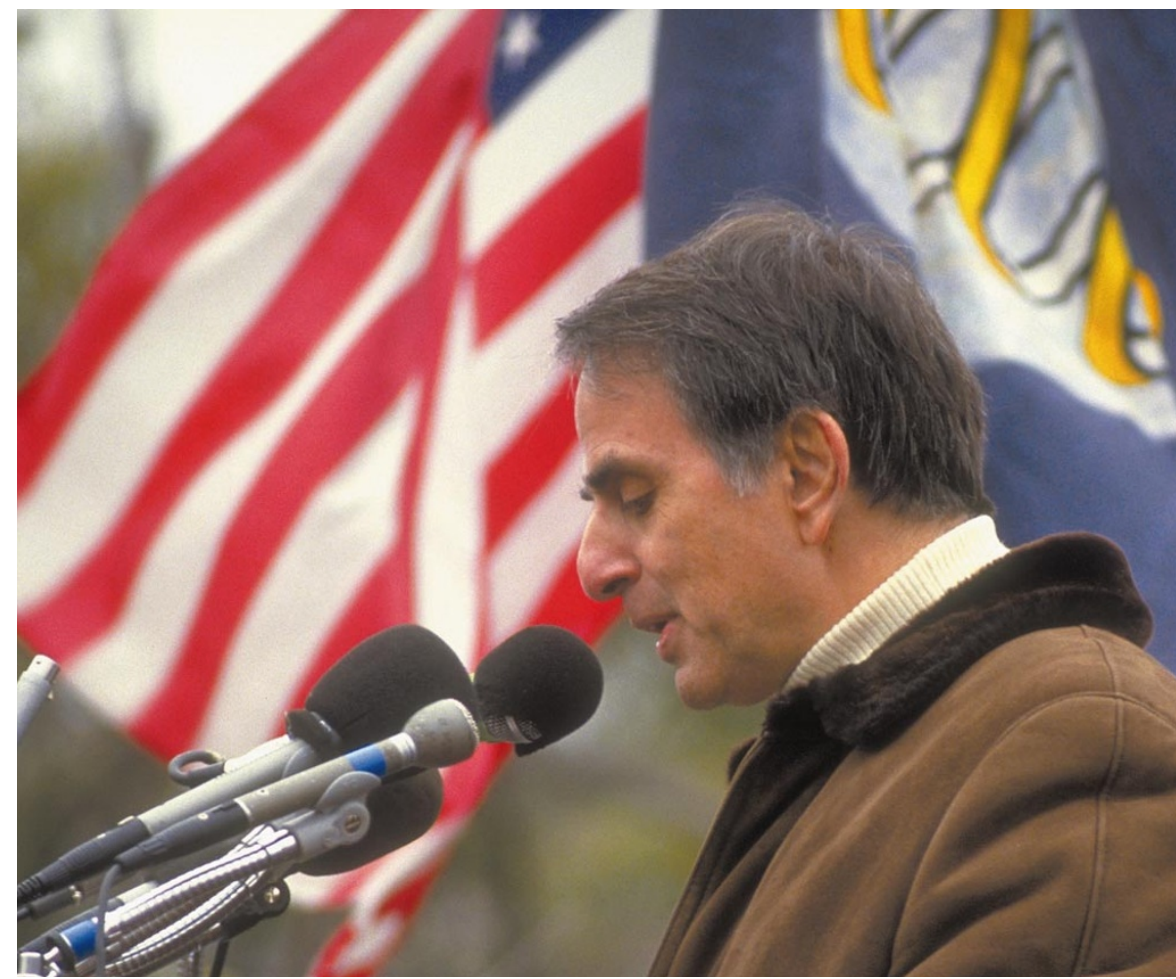

A man for all seasons: Sagan speaking as an anti-nuclear advocate at the Great Peace March in 1986.

Both Poundstone and Davidson shed new light on the heated debate that occurred over this affair. Based on sources in the academy, some of whom requested anonymity, it becomes clear that Sagan's opponents felt the greatest contempt for his popularization of science. There was also an accusation that Sagan failed in his Venus greenhouse work to credit Rupert Wildt, who first proposed the idea. But, as Davidson notes, the opening sentence of the introduction to Venus in Sagan's thesis lists Wildt by name, acknowledges his precedence and cites Wildt's 1940 paper.

Lynn Margulis, a participant in the academy's debate, later wrote to Sagan, saying that his opponents were "jealous of your communication skills, charm, good looks, and outspoken attitude". Poundstone tells us that Sagan guessed the topic of Margulis' letter and asked his wife, Ann Druyan, to read it to him, omitting names. This is consistent with Carl's account to me; he preferred not to know the names of those who spoke against him because that could make it harder to work with them in the future. When giving me this account, true to his respect for others' privacy, Carl also protected the name of the letter's author. Margulis subsequently shared her letter with Poundstone and Davidson.

It is only fair to tell the reader that Carl Sagan was my colleague and friend for more than a decade. Like all of us, he was flawed. In one of his last popular books, the grim Demon-Haunted World (Ballantine, 1997), Carl offered a list of his scientific mistakes. In the same book, he also reiterated one of his greatest concerns: "we humans have a talent for deceiving ourselves. Skepticism must be a component of the explorer's toolkit, or we will lose our way." Biographers might pay heed to this warning.

Christopher Chyba is at the SETI Institute, 2035 Landings Drive, Mountain View,

California 94404, and in the Department of Geological and Environmental Sciences, Stanford University, Stanford, California 94305, USA.

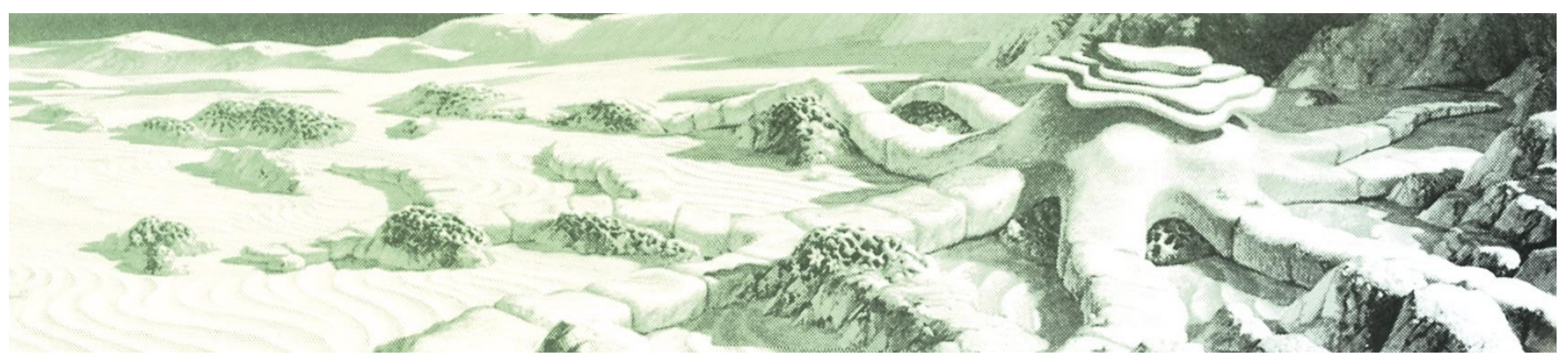

Life on Mars: a Martian 'petrophage’, inspired by Sagan and Joshua Lederberg's assessments preceding the Viking mission to Mars. 